\title{
Acid Elution of Aluminum and Calcium from Human Deciduous Enamel in Relation to Dental Caries
}

\author{
Koji Watanabe1,2*, Toshiko Tanaka ${ }^{3}$, Ayaka Enomoto², Katsura Saeki4, \\ Shigenori Kawagishi' ${ }^{4}$ Hideaki Nakashima ${ }^{3}$, Kenshi Maki ${ }^{4}$, Shigeru Watanabe ${ }^{1}$ \\ ${ }^{1}$ Division of Pediatric Dentistry, Department of Human Development and Fostering, Meikai University School of \\ Dentistry, Sakado, Japan \\ ${ }^{2}$ Division of Developmental Stomatognathic Function Science, Department of Health Promotion, Kyushu Dental \\ University, Kitakyushu, Japan \\ ${ }^{3}$ Division of Surgery, Department of Health Promotion, Kyushu Dental University, Kitakyushu, Japan \\ ${ }^{4}$ Division of Multidisciplinary Studies, Department of Health Promotion, Kyushu Dental University, Kitakyushu, \\ Japan \\ Email: ${ }^{*} k$-watanabe@dent.meikai.ac.jp
}

Received 20 January 2016; accepted 26 February 2016; published 29 February 2016

Copyright (C) 2016 by authors and Scientific Research Publishing Inc.

This work is licensed under the Creative Commons Attribution International License (CC BY). http://creativecommons.org/licenses/by/4.0/

(c) (i) Open Access

\section{Abstract}

Although aluminum itself was reported to prevent dental caries, previous in vitro studies reported that the aluminum level in the whole saliva of children was independent of caries prevalence. Purposes of this study were to compare the elution levels of aluminum and calcium from deciduous enamel into acidic artificial saliva, and determine whether the degree of aluminum elution reflects individual caries risk. One hundred and eleven extracted human deciduous teeth were collected. Concentrations of aluminum and calcium eluted from sound regions of enamel into artificial saliva (pH 6.2 or 5.5) were determined using atomic absorption spectrophotometry. One hundred and four and $\mathbf{1 0 8}$ available data samples were obtained for aluminum and calcium evaluation, respectively, and were compared based on the sex, tooth type, caries history, and the number of the donor's carious teeth at each $\mathrm{pH}$. Calcium elution was not affected by the sex; however, more aluminum was eluted from boys' than from girls' teeth at pH 5.5. The aluminum release depended on the tooth type, and was significantly higher in incisors than in molars at a pH of 5.5. In relation to the caries history, aluminum (at pH 5.5) and calcium (at pH 6.2) dissolved more from sound regions of the enamel of caries-experienced teeth than from the enamel of teeth without caries experience. Moreover, aluminum markedly dissolved from enamel in artificial saliva at both pH 6.2 and 5.5 when the donor had more carious teeth, regardless of the presence or absence of

\footnotetext{
${ }^{*}$ Corresponding author.
} 
caries experience in the sampled teeth. There is a possibility that the rate of aluminum elution from enamel into acidic fluid reflects individual caries sensitivity.

\author{
Keywords
}

Aluminum, Elution, Deciduous Enamel, Dental Caries, Artificial Saliva

\title{
1. Introduction
}

Demineralization of enamel is a serious health problem throughout the world and it involves the process of dissolution of hydroxyapatite minerals [1]. Remineralization is the reverse process, involving elements such as calcium and phosphate. Enamel is continuously de- and remineralized in the oral cavity by pathological and protective factors. Pathological factors consist of acid-producing bacteria, sub-normal saliva flow and/or function, and frequent eating/drinking of fermentable carbohydrates. Protective factors consist of saliva flow and its components: fluoride, calcium, and phosphate. When the pathological factors outweigh the protective factors, the enamel crystals begin to collapse [2] [3].

Aluminum ( $\mathrm{Al}$ ) is the most widely distributed metal in the outer crust of the earth; however, it exists only in trace amounts in living organisms. Al is biologically non-essential for humans, and is taken into the human body mainly through drinking water [4]. Although most of the ingested Al is eliminated by the kidneys, it accumulates in some tissues and induces neurodegenerative diseases or osteomalacia when the tissue concentration is excessive [5]-[8]. Al also exists in enamel, and has been reported to inhibit the growth and adhesion of acidproducing oral bacteria [9]-[11].

Although Al itself was reported to be cariostatic, previous in vitro studies reported that the $\mathrm{Al}$ level in the whole saliva of children was independent of caries prevalence, but, strontium (Sr), silver (Ag), copper (Cu) and iron (Fe) concentrations were dependent [12]-[14]. In this study, the amount of Al eluted from enamel into artificial saliva at an acid $\mathrm{pH}$ was measured and compared based on the caries experience of each tooth sample or individual donor, and also, whether or not the Al elution level reflected individual caries risk in comparison with that of calcium $(\mathrm{Ca})$ elution.

\section{Materials and Methods}

\subsection{Collection of Deciduous Teeth}

One hundred and eleven human deciduous teeth with physiological root resorption were collected, after extraction at Kyushu Dental University Hospital or some dental offices in Kitakyushu City from June 2009 to January 2010. The teeth were extracted under local anesthesia because they still existed in the oral cavity even when they had to be replaced by permanent ones. It was confirmed that there were no infection or pathological lesion around the roots by radiographs before extraction. The study protocol was approved by the ethics committee of Kyushu Dental University (approval number: 09-01). After the purpose and content of this study were sufficiently explained to all subjects and their parents, written consent was obtained. When tooth sampling was carried out, an oral examination and a questionnaire survey on the use of fluoride were also conducted. Plaque, connective tissue, and other substances were removed from the surface of each collected tooth by a micro-motor (NSK, Tokyo, Japan). The teeth were ultrasonically washed with ultrapure water 3 times for 10 minutes each time, stored individually in sterilized test tubes [12]-[14], and dried at room temperature for 2 - 4 weeks until elution analysis.

\subsection{Classification of the Sample Teeth}

The sample teeth were classified based on both the oral examination and a direct inspection [15], into a sound tooth (ST) group without past or current caries experience, and a caries-experienced tooth (CE) group with past or current caries experience. The CE group was additionally divided into two groups based on the presence or absence of caries treatment: an untreated carious tooth (UC) group which had untreated lesions in enamel and a treated carious tooth (TC) group in which the teeth had once experienced caries but the lesions were completely 
eliminated and filled by restorations. Treated carious teeth with secondary caries lesions were classified as the TC group.

\subsection{Chemicals}

The following chemicals were obtained from Wako Pure Chemical Ind. (Osaka, Japan): nitric acid for ultratrace analysis, $5 \mathrm{~mol} / \mathrm{L}$ sodium hydroxide solution for volumetric analysis, hydrochloric acid for ultratrace analysis, sodium chloride as reference material for volumetric analysis, and DL-lactic acid (S grade), ammonium chloride (S grade), potassium chloride (S grade), aluminum standard solution, and calcium standard solution for atomic absorption analysis. Citranox ${ }^{\circledR}$ Liquid acid detergent for trace metal analysis was purchased from NIPPON Genetics Co., Ltd. (Tokyo, Japan).

\subsection{Elution Analysis}

Caries lesions and metal restorations were removed from the sample teeth and the sound enamel surface was covered with vinyl tape. Since the sound enamel surface was curved, it was covered with vinyl tape that was cut into pieces carefully to fit and cover the curved surface completely without overlap or gap. Then, the area of the newly exposed surface made by elimination of the caries lesions or metal restorations was coated with quickcure resin (Shofu, Kyoto, Japan). On polymerizing the resin, the vinyl tape was peeled off from the enamel surface, and the dimensions of the area were calculated using a planimeter (Marble, Sydney, Australia). Each sample was ultrasonically washed with ultrapure water 3 times for 5 minutes each time, and then put into a Teflon ${ }^{\circledR}$ vessel (Sanplatec, Osaka, Japan). This procedure allowed only sound enamel regions to be exposed to artificial saliva. Artificial saliva was prepared employing the method described in the BS 6684 British Standard Specification for Safety Harnesses, 1987 [16]. A solution obtained by dissolving $\mathrm{NaCl}$ (4.5 g), $\mathrm{KCl}$ ( $0.3 \mathrm{~g}), \mathrm{Na}_{2} \mathrm{SO}_{4}(0.4$ g), $\mathrm{NH}_{4} \mathrm{Cl}(0.4 \mathrm{~g})$, DL-lactic acid $(3.0 \mathrm{~g})$, and urea $(0.2 \mathrm{~g})$ in ultrapure water $(1000 \mathrm{~mL})$ was adjusted to $\mathrm{pH} 6.2$ or 5.5 with $5 \mathrm{~mol} / \mathrm{L} \mathrm{NaOH}$. Argon substitution was performed to maintain the $\mathrm{pH}$ in the artificial saliva, and then each sample tooth was immersed in $4.05 \mathrm{~mL}$ of artificial saliva and continuously shaken slowly for 4 hours at $\mathrm{pH} 6.2$ and $37^{\circ} \mathrm{C}$ ). The sample was subsequently immersed in $4.05 \mathrm{~mL}$ of artificial saliva at $\mathrm{pH} 5.5$ and $37^{\circ} \mathrm{C}$ and shaken. After the sample was removed from the Teflon ${ }^{\circledR}$ vessel, $0.45 \mathrm{~mL}$ of $1 \mathrm{~mol} / \mathrm{L} \mathrm{HNO}_{3}$ was added to the artificial saliva solution. Two Teflon ${ }^{\circledR}$ vessels which contained only $\mathrm{HNO}_{3}$ were prepared per 20 samples under the same conditions to test for chemical purity and any contamination.

\subsection{Determination of $\mathrm{Al}$ and Ca Concentrations}

The concentration of Al was determined by injecting $10 \mu \mathrm{L}$ of an artificial saliva sample into a pyro-coated graphite cuvette (Model 180-7444; Hitachi, Tokyo, Japan) using flameless atomic absorption spectrophotometry (model Z-8200; Hitachi, Tokyo, Japan). The furnace thermal programs were: drying at $80^{\circ} \mathrm{C}-120^{\circ} \mathrm{C}$ for $30 \mathrm{~s}$; ashing at $750^{\circ} \mathrm{C}$ for $20 \mathrm{~s}$; atomization at $2900^{\circ} \mathrm{C}$ for $10 \mathrm{~s}$; and cleaning at $3000^{\circ} \mathrm{C}$ for $3 \mathrm{~s}$. The Ca concentration was determined by the flame method using the same model. The sample was atomized by aspiration in an air-acetylene flame after 10 -times dilution with $0.1 \mathrm{~mol} / \mathrm{L} \mathrm{HNO}_{3}$. Each element level was determined by the calibration curve method using standard solutions for atomic absorption spectrophotometry. The samples and standard solutions were diluted with $0.1 \mathrm{~mol} / \mathrm{L} \mathrm{HNO}_{3}$ as necessary. Each sample was measured in duplicate. The standard curve was recalibrated every 5 samples. Concentrations of $\mathrm{Al}$ and Ca were calculated as the amount of elution per unit area from the enamel surface to artificial saliva [14] [15].

\subsection{Statistical Analysis}

The Smirnov-Grubbs' outlier test was performed to eliminate singular data [14], resulting in obtaining 104 and 108 available data samples for analyses of $\mathrm{Al}$ and Ca concentrations, respectively (Table 1). Values in the tables and figures are shown as the mean \pm S.E. The significance of differences between two groups was analyzed by the unpaired Student's $t$-test for equal variance or Welch's correction for unequal variance using Ekuseru-Toukei 2010 (Social Survey Research Information Co., Ltd., Tokyo, Japan). For comparison among 3 independent groups, Tukey's HSD (for homogeneous variance) or Dunnet's method (for inhomogeneous variance) was performed using SPSS Statistics 19 (IBM Japan, Tokyo, Japan). A p-value $<0.05$ was considered significant. 
Table 1. Clinical characteristics of the children.

\begin{tabular}{cccc}
\hline Factors & & & Element \\
& & Al & Ca \\
\hline Total subjects $(n)$ & & 104 & 108 \\
Sex $(n)$ & Male & 62 & 65 \\
& Female & 42 & 43 \\
Age (years) & Mean \pm S.D. & $9.1 \pm 2.0$ & $5.1 \pm 2.0$ \\
& Range & $5-14$ & 21 \\
Tooth types $(n)$ & Incisors & 18 & 18 \\
& Canines & 17 & 69 \\
Tooth condition $(n)$ & Molars & 69 & 41 \\
& Sound & 38 & 67 \\
\hline
\end{tabular}

\section{Results}

\subsection{Eluted Al and Ca Levels in the ST Group}

As shown in Table 2, Al concentrations eluted from sound deciduous enamel without caries experience of the ST group into artificial saliva at $\mathrm{pH}$ values of 6.2 and 5.5 were measured. The Al level was additionally compared based on the sex and tooth type at each $\mathrm{pH}$ value. The eluted Al level was higher in boys than in girls, with a significant difference at a pH of 5.5 ( $\mathrm{p}<0.01)$. Different tooth types showed variations in Al levels. Especially, the $\mathrm{Al}$ concentration of incisors was significantly higher than that of molars $(\mathrm{p}<0.05)$ at a $\mathrm{pH}$ of 5.5 . In the same way, Ca levels were compared. No significant difference was found in the eluted Ca levels in comparisons based on sex or tooth type.

\subsection{Al and Ca Elution Levels Related to Dental Caries}

As shown in Table 3, Al elution levels in the CE group at pH values of 6.2 and 5.5 were measured. A significant difference was found in the eluted $\mathrm{Al}$ level between the ST and CE groups at a pH of 5.5 (p $<0.05$ ). In order to evaluate whether or not the existence of caries lesions affected the amount of Al elution, the eluted Al level was additionally compared between the UC and TC groups. Although the eluted Al level in the CE group was significantly higher than that in the ST group at a $\mathrm{pH}$ of 5.5, as mentioned before, no significant difference was found in the eluted $\mathrm{Al}$ level between the UC and TC groups at $\mathrm{pH}$ 5.5. Ca elution levels in the $\mathrm{CE}$ group at $\mathrm{pH}$ values of 6.2 and 5.5 were also measured. A significant difference was found in the eluted Ca level between the ST and CE groups at a pH of 6.2 (p < 0.05) (Table 3). The eluted Ca level was similar between the UC and TC groups at a $\mathrm{pH}$ of 6.2 (Table 3 ).

Some of the donor children in the ST group had caries-experienced teeth, even though the sampled tooth was sound. So, the ST and CE groups were further divided into three subgroups based on the number of each individual donor's carious teeth, and then $\mathrm{Al}$ and Ca elution levels were compared among the subgroups at a pH of 6.2 or 5.5. The ST group was further classified into: a 0 caries-experienced teeth (ST0) subgroup: children who provided a tooth without past or current caries experience and had no caries-experienced teeth in their oral cavity; a 1 - 5 caries-experienced teeth (ST1-5) subgroup: children who provided a tooth without past or current caries experience, but had 1 - 5 caries-experienced teeth; and a 6 or more caries-experienced teeth (ST6-) subgroup: children who provided a tooth without past or current caries experience, but had 6 or more caries-experienced teeth. The CE group was also further divided into CE1-5, CE6-10, and CE11-subgroups in a similar way as the ST group. As shown in Figure 1, the eluted Al level in the ST6-subgroup was markedly higher: it was significantly higher in the ST6- $\left(81.8 \pm 13.2 \mathrm{ng} / \mathrm{cm}^{2}\right)$ than in the ST1-5 $\left(42.2 \pm 6.4 \mathrm{ng} / \mathrm{cm}^{2}\right)$ subgroup at a $\mathrm{pH}$ of $6.2(\mathrm{p}<$ 
Table 2. Eluted $\mathrm{Al}$ and Ca levels in the ST group depending on sex and tooth type.

\begin{tabular}{|c|c|c|c|c|c|c|}
\hline \multirow[t]{2}{*}{ Parameter } & \multicolumn{3}{|c|}{$\mathrm{Al}\left(\mathrm{ng} / \mathrm{cm}^{2}\right)$} & \multicolumn{3}{|c|}{$\mathrm{Ca}\left(\mu \mathrm{g} / \mathrm{cm}^{2}\right)$} \\
\hline & Number & pH 6.2 & pH 5.5 & Number & pH 6.2 & pH 5.5 \\
\hline Mean \pm S.D. & 38 & $52.7 \pm 5.1$ & $57.7 \pm 5.9$ & 41 & $26.8 \pm 1.6$ & $48.7 \pm 3.1$ \\
\hline \multicolumn{7}{|l|}{ Sex } \\
\hline Male & 16 & $61.7 \pm 8.4$ & $78.5 \pm 10.07$ & 18 & $28.7 \pm 2.4$ & $54.9 \pm 5.7$ \\
\hline Female & 22 & $47.0 \pm 6.2$ & $43.4 \pm 5.6]$ & 23 & $25.3 \pm 2.1$ & $43.8 \pm 3.0$ \\
\hline \multicolumn{7}{|l|}{ Tooth types } \\
\hline Incisors & 14 & $65.0 \pm 8.2$ & $76.4 \pm 11.17$ & 17 & $24.7 \pm 1.6$ & $46.2 \pm 2.6$ \\
\hline Canines & 12 & $53.7 \pm 10.4$ & $55.1 \pm 6.4$ & 13 & $25.5 \pm 2.0$ & $46.7 \pm 3.7$ \\
\hline Molars & 12 & $37.1 \pm 5.8$ & لـ & 11 & $25.6 \pm 1.7$ & $44.0 \pm 5.7$ \\
\hline
\end{tabular}

Table 3. Eluted Al and Ca levels in the ST, CE, UC, and TC groups.

\begin{tabular}{|c|c|c|c|c|c|c|}
\hline \multirow{2}{*}{$\begin{array}{c}\text { Parameter } \\
\text { Group }\end{array}$} & \multicolumn{3}{|c|}{$\mathrm{Al}\left(\mathrm{ng} / \mathrm{cm}^{2}\right)$} & \multicolumn{3}{|c|}{$\mathrm{Ca}\left(\mu \mathrm{g} / \mathrm{cm}^{2}\right)$} \\
\hline & Number & pH 6.2 & pH 5.5 & Number & pH 6.2 & pH 5.5 \\
\hline ST & 38 & $52.7 \pm 5.1$ & $57.7 \pm 5.97$ & 41 & $26.8 \pm 1.67$ & $48.7 \pm 3.1$ \\
\hline CE & 66 & $64.8 \pm 5.3$ & $93.4 \pm 63.7]^{*}$ & 67 & $32.8 \pm 2.0{ }^{*}$ & $51.5 \pm 2.6$ \\
\hline $\mathrm{UC}$ & 22 & $67.8 \pm 10.1$ & $98.3 \pm 13.0$ & 21 & $33.6 \pm 4.9$ & $45.9 \pm 4.7$ \\
\hline TC & 44 & $63.1 \pm 6.1$ & $90.7 \pm 10.6$ & 46 & $32.4 \pm 1.9$ & $54.0 \pm 3.1$ \\
\hline
\end{tabular}

$$
{ }^{*} \mathrm{p}<0.05 \text {. }
$$

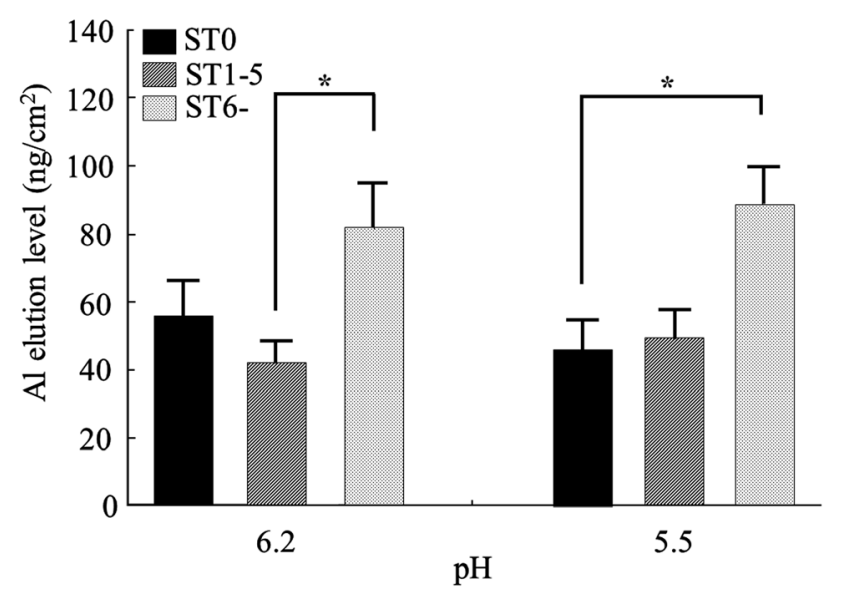

Figure 1. Al elution level based on the number of donors' carious teeth in the ST group. The ST6-subgroup showed high Al elution levels at both $\mathrm{pH} 6.2$ and 5.5 (both $\mathrm{p}<0.05$ ).

0.05), and was significantly higher in the ST6 $\left(88.7 \pm 10.8 \mathrm{ng} / \mathrm{cm}^{2}\right)$ than ST0 $\left(45.7 \pm 9.4 \mathrm{ng} / \mathrm{cm}^{2}\right)$ subgroup at a pH of 5.5 ( $\mathrm{p}<0.05)$. Figure 2 shows a comparison of eluted Ca levels among the subgroups in the ST group. The eluted Ca level in the ST6- $\left(65.8 \pm 6.9 \mu \mathrm{g} / \mathrm{cm}^{2}\right)$ was significantly higher than those in the ST0 $(40.6 \pm 4.1$ $\left.\mu \mathrm{g} / \mathrm{cm}^{2}\right)(\mathrm{p}<0.01)$ and ST1-5 $\left(43.3 \pm 2.8 \mu \mathrm{g} / \mathrm{cm}^{2}\right)(\mathrm{p}<0.01)$ subgroups at a $\mathrm{pH}$ of 5.5 . In the comparisons among the subgroups in the $\mathrm{CE}$ group, the eluted $\mathrm{Al}$ level rose as the number of carious teeth increased, showing a significant difference between the CE11-(83.1 $\left.\pm 10.5 \mathrm{ng} / \mathrm{cm}^{2}\right)$ and CE1-5 (50.2 $\left.\pm 5.0 \mathrm{ng} / \mathrm{cm}^{2}\right)$ subgroups at a $\mathrm{pH}$ of $6.2(\mathrm{p}<0.05)$ (Figure 3). The eluted Ca level also rose according to the increase in the number of carious teeth, showing a significant difference between the CE11-(59.5 $\left.\pm 5.3 \mu \mathrm{g} / \mathrm{cm}^{2}\right)$ and CE1-5 $\left(44.4 \pm 3.2 \mu \mathrm{g} / \mathrm{cm}^{2}\right)$ subgroups at a $\mathrm{pH}$ of $5.5(\mathrm{p}<0.05)$ (Figure 4). 


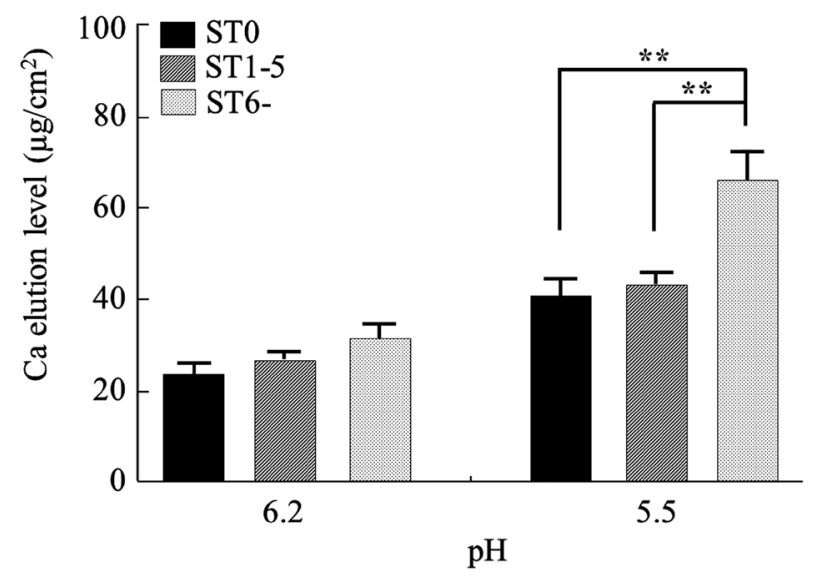

Figure 2. Ca elution level based on the number of donors' carious teeth in the ST group. The ST6-subgroup showed a high Ca elution level only at pH $5.5(\mathrm{p}<0.01)$.

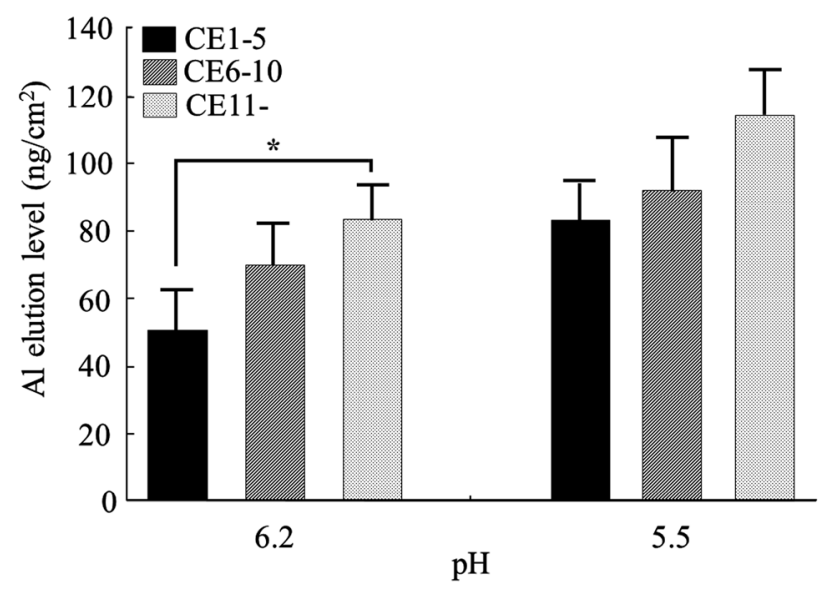

Figure 3. Al elution level based on the number of donors' carious teeth in the CE group. The CE11-subgroup showed a high Al elution level only at $\mathrm{pH} 6.2(\mathrm{p}<0.05)$.

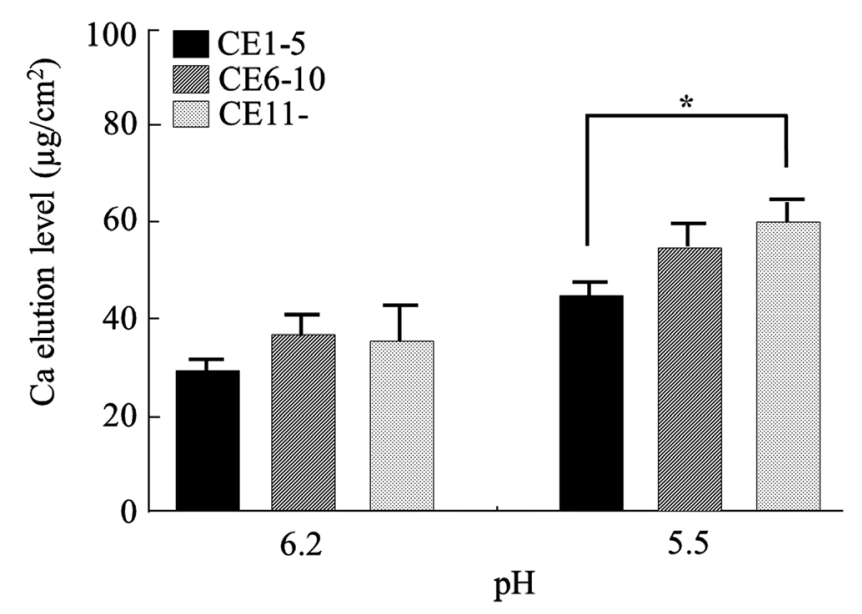

Figure 4. Ca elution level based on the number of donors' carious teeth in the $\mathrm{CE}$ group. The CE11-subgroup showed a high Ca elution level only at pH $5.5(\mathrm{p}<0.05)$. 


\section{Discussion}

While $\mathrm{Al}$ and Ca levels are appropriately maintained in serum by the homeostasis of living organisms [4] [17]-[19], the elution level of enamel components varies according to the intraoral surroundings. For example, Ca elutes when hydroxyapatite is undersaturated in the oral fluid which surrounds the enamel surface; on the other hand, it may deposit in early caries lesions when hydroxyapatite is oversaturated in the oral fluid. Although the solubility of Ca depends on the concentration of $\mathrm{Ca}^{2+}$ and $\mathrm{PO}_{4}^{3-}$ in the oral fluid, the $\mathrm{pH}$ of plaque fluid in caries-positive individuals one hour after sucrose rinses was reported to be about 5.9 [20], and the critical $\mathrm{pH}$ of human deciduous enamel is generally defined as 5.7 - 6.2 [21]. Therefore, the pH values of artificial saliva used in this study were decided on as 6.2 at the upper limit of the critical pH of human enamel, and 5.5, which was sufficient to demineralize human enamel. In this study, the amount of $\mathrm{Al}$ and Ca eluted from enamel was calculated by dividing the total eluted amount into artificial saliva by the dimensions of the exposed enamel surface made by vinyl tape. The limitation of this study was that the vinyl tapes cannot prevent acid exposure beneath the enamel surface, hence they can apart enamel region into acid exposure and non-acid exposure areas accurately only on the enamel surface.

Tanaka et al. (2014) [15] reported in their in vitro study that the Al concentration in sound deciduous enamel of boys (40.0 $\pm 36.6 \mu \mathrm{g} / \mathrm{g}$; mean \pm S.D.) and girls $(45.6 \pm 38.1 \mu \mathrm{g} / \mathrm{g}$, ) was similar and that the Al level in sound deciduous enamel of incisors $(45.3 \pm 38.2 \mu \mathrm{g} / \mathrm{g})$ was significantly higher than that of canines $(19.6 \pm 11.2 \mu \mathrm{g} / \mathrm{g})$ ( $\mathrm{p}<0.001)$. In the present study, $\mathrm{Al}$ and Ca levels eluted from enamel were not affected by the sex at $\mathrm{pH} 6.2$ (around the borderline of demineralization), and the eluted $\mathrm{Al}$ level in incisors was significantly higher than that in molars at pH 5.5 (enough to demineralize human enamel), supported by a previous study that reported a higher level of $\mathrm{Al}$ distributed in incisors. Interestingly, at $\mathrm{pH}$ 5.5, the eluted $\mathrm{Al}$ level was higher in boys than in girls. Enamel is secreted by ameloblasts in alveolar bone during tooth formation. Secreted enamel is calcified by Ca and other minerals from serum before tooth eruption and from the surroundings such as oral fluid, food, and water after eruption. Such a process of calcification suggests that enamel itself does not consist of cells and that it does not undergo regular physiological turnover, as observed in other tissues. Hence, the difference in the Al elution level could be derived from the difference in individual daily habits which affect the intraoral condition rather than for a biological reason. Fluoride application affects individual acid resistance of enamel, so the use of fluoride was investigated as one of the possible habits which could cause the difference in the Al elution level; however, no apparent difference was found in the use of fluoride between boys and girls (data not shown). So, further research is needed to explain the sexual difference in the Al elution level.

In relation to dental caries, Al was eluted more from sound regions of caries-experienced enamel than from enamel without caries experience at pH 5.5 (Table 3), and the eluted Al level was not affected by whether or not the lesion had been treated. Figures 1-3 also indicate that the level of Al elution increased as the number of the donor's carious teeth increased, regardless of the presence or absence of remaining carious lesions in the sampled tooth itself. This suggested that Al eluted more from enamel when the donor is likely to be suffering from dental caries. Moreover, in a previous study of the Al concentration in deciduous enamel of children [15], a significantly higher concentration of $\mathrm{Al}$ was found in sound enamel than in enamel with carious lesions. Putt and Kleber (1995) [22] reported in their in vitro study that the topical application of Al solutions significantly inhibited caries formation in rats, and Höök et al. (1994) [23] and Koletsi-Kounari et al. (2012) [24] discussed the combined effects of $\mathrm{Al}$ and $\mathrm{F}$ in their in vitro studies using bovine enamel, and concluded that the topical application of $\mathrm{Al}$ and $\mathrm{F}$ promoted enamel remineralization or prevented acid demineralization. Considering these results and reports, it is suggested that, when an amount of Al with a cariostatic property elutes from enamel, the person can be prone to dental caries, and the amount of Al lost from enamel could be considered as one of the parameters of individual caries risk. Of course, if a carious tooth is treated and filled with some material containing $\mathrm{Al}$, the $\mathrm{Al}$ could also elute from the restoration [25]. However, Al elution from restorations can be ignored in this study because the eluted Al level was measured only in the sound region of enamel. The authors previously reported the $\mathrm{Al}$ concentration in whole saliva of children $(0.093 \pm 0.136 \mu \mathrm{g} / \mathrm{mL}$; mean \pm S.D. $)$, and reported that there was no relationship between the Al level and children's caries prevalence [14]. However, Al elution from enamel into whole saliva could be so small that the difference of the Al level in whole saliva cannot be detected between children with and without caries teeth. Whole saliva could contain Al from various sources. The $\mathrm{pH}$ of the whole saliva samples was around 7.0 when the authors evaluated the relationship between the Al concentration and caries prevalence, which meant the samples were not subjected to acid surroundings through- 
out the examination. On the other hand, in the present study, tooth samples were exposed to acid surroundings in the process of demineralization. Thus it is suggested that the difference between normal and caries-prone children in the $\mathrm{Al}$ level in saliva was found only in the acid surroundings. Enamel is demineralized when the $\mathrm{pH}$ in the oral cavity decreases below the critical $\mathrm{pH}$ due to both acid food and drink intake. Moreover, oral $\mathrm{pH}$ is also decreased below the critical $\mathrm{pH}$ by acid production of oral bacteria after sucrose consumption and is kept in acid for more than one hour after sucrose intake [20] in their daily life. Hence it was considered that the Al elution level from enamel in the acid surroundings could be more markedly affected by caries proneness than the Al level in the whole saliva around a $\mathrm{pH}$ of 7.0.

The characteristics of $\mathrm{Al}$ behavior in acid surroundings based on the $\mathrm{pH}$, sex, tooth type, and oral condition was revealed in the comparison with $\mathrm{Ca}$. In Table 2, the dissolved level of Al from enamel was almost stable between $\mathrm{pH}$ values of 5.5 and 6.2, although the eluted level of Ca was markedly higher at $\mathrm{pH} 5.5$ than at $\mathrm{pH} 6.2$ (Table 2). These findings suggest that the Al elution could be higher near the enamel surface than in deeper regions, just like with strontium [26], fluoride [27], and zinc [28], which have been found to be distributed mainly near the enamel surface. They indicated that the Al elution level might not be merely affected by the $\mathrm{pH}$ in the present study. Ca eluted more from caries-experienced enamel than from enamel without such experience at $\mathrm{pH}$ 6.2 (Table 3), while the same tendency was observed in Al behavior at pH 5.5 (Table 3). In terms of elution of the two elements, these findings indicate that both $\mathrm{Ca}$ and $\mathrm{Al}$ dissolved more from caries-experienced enamel than from enamel without such experience, although elution occurred at a different pH. It is suggested that Ca eluted more from caries-prone enamel than from enamel less likely to be demineralized around the higher (neutral side) borderline of the critical $\mathrm{pH}$; however, almost the same amount of Ca was eluted from both the caries-prone enamel and that less likely to be demineralized when exposed to a $\mathrm{pH}$ high enough to cause demineralization. It is also suggested that $\mathrm{Al}$ eluted more from caries-prone enamel than from that less likely to be demineralized around the higher (neutral side) borderline of the critical $\mathrm{pH}$; however, almost the same amount of Ca was eluted from both the caries-prone enamel and that less likely to be demineralized when exposed to a $\mathrm{pH}$ low enough to cause demineralization. It is also suggested that Al eluted more from caries-prone enamel than from that less likely to be demineralized when at a $\mathrm{pH}$ of 5.5, which was enough for demineralization. Interestingly, when focusing on the number of donors' carious teeth, abundant Al dissolved from enamel when the donor had more carious teeth at $\mathrm{pH} 6.2$ as well as at pH 5.5, even though the sampled enamel itself had no experience of dental caries (Figure 1). A similar tendency was found when the Al level was measured in sound regions of caries-experienced enamel (Figure 3). On the other hand, abundant Ca eluted from enamel when the donor had more carious teeth only at $\mathrm{pH} 5.5$, regardless of the presence or absence of caries experience. These findings indicate that Ca eluted by acid demineralization in a typical way [29]; however, Al did not react in the same way as Ca in acid demineralization; the sensitivity of enamel to dental caries could affect the property of Al elution in acid surroundings. Although the reason has not been clarified, it was suggested that Al eluted more from enamel at a $\mathrm{pH}$ of 5.5 when the person was prone to dental caries. Moreover, even at a $\mathrm{pH}$ of 6.2 , it was suggested that the $\mathrm{Al}$ elution level reflects the number of individual carious teeth. Considering the result that $\mathrm{Al}$ eluted more from caries-prone enamel than from normal enamel, it could be speculated that caries-prone enamel releases $\mathrm{Al}$ which was reported to inhibit demineralization in bovine enamel in an in vitro study [23], to reduce the formation and progression of caries in rats by topical application in an in vivo study [22], and to inhibit caries development by mouthrinse in caries-prone children [30] in order to protect enamel itself against demineralization.

\section{Conclusions}

1) Ca eluted more from sound region of caries experienced deciduous enamel than from sound deciduous enamel at the $\mathrm{pH}$ value of 6.2. The eluted Ca level was statistically equal at the $\mathrm{pH}$ value of 5.5 which was below critical $\mathrm{pH}$ of enamel.

2) The elution level of Al from deciduous enamel was statistically equal between sound deciduous enamel and sound region of caries experienced deciduous enamel at the $\mathrm{pH}$ value of 6.2, however, Al eluted more from sound region of caries experienced deciduous enamel than from sound deciduous enamel at the $\mathrm{pH}$ value of 5.5.

3) In both sound deciduous enamel and sound region of caries experienced deciduous enamel, Al elution level was high when the donor children had more carious teeth in their mouth.

4) It was suggested that $\mathrm{Al}$ elution level increased when caries sensitivity of the person was high. 


\section{Acknowledgements}

This manuscript was subsidized by JSPS KAKENHI Grant Number 15K20607.

\section{References}

[1] Featherstone, J.D. (2000) The Science and Practice of Caries Prevention. The Journal of the American Dental Association, 131, 887-899.

[2] Murayama, R., Furuichi, T., Yokokawa, M., Takahashi, F., Kawamoto, R., Takamizawa, T., Kurokawa, H. and Miyazaki, M. (2012) Ultrasonic Investigation of the Effect of S-PRG Filler-Containing Coating Material on Bovine Tooth Demineralization. Dental Materials Journal, 31, 954-959. http://dx.doi.org/10.4012/dmj.2012-153

[3] Featherstone, J.D. (2004) The Caries Balance: The Basis for Caries Management by Risk Assessment. Oral Health \& Preventive Dentistry, 2, 259-264.

[4] Willhite, C.C., Ball, G.L. and McLellan, C.J. (2012) Total Allowable Concentrations of Monomeric Inorganic Aluminum and Hydrated Aluminum Silicates in Drinking Water. Critical Reviews in Toxicology, 42, 358-442. http://dx.doi.org/10.3109/10408444.2012.674101

[5] Alfrey, A.C. (1984) Aluminum Toxicity. The Bulletin of the New York Academy of Medicine, 60, 210-212.

[6] Gómez, M., Esparza, J.L., Cabré, M., García, T. and Domingo, J.L. (2008) Aluminum Exposure through the Diet: Metal Levels in AbetaPP Transgenic Mice, a Model for Alzheimer's Disease. Toxicology, 249, 214-219. http://dx.doi.org/10.1016/j.tox.2008.05.004

[7] Rüster, M., Abendroth, K., Lehmann, G. and Stein, G. (2002) Aluminum Deposition in the Bone of Patients with Chronic Renal Failure-Detection of Aluminum Accumulation without Signs of Aluminum Toxicity in Bone Using Acid Solochromeazurine. Clinical Nephrology, 58, 305-312. http://dx.doi.org/10.5414/CNP58305

[8] Kawahara, M. (2005) Effects of Aluminum on the Nervous System and Its Possible Link with Neurodegenerative Diseases. Journal of Alzheimer's Disease, 8, 171-182.

[9] Regolati, B., Schait, A., Schmid, R. and Mühlemann, H.R. (1974) The Effect of Titanium, Aluminum and Fluoride on Rat Caries. Helvetica Odontologica Acta, 18, 92-96.

[10] Brown, D.T., Miller, C.H. and Maupin, D.E. (1991) The Effect of Sucralfate on the Growth of Cariogenic Streptococci. The Journal of Prosthetic Dentistry, 66, 256-260. http://dx.doi.org/10.1016/S0022-3913(05)80057-5

[11] Olsson, J. and Odham, G. (1978) Effect of Inorganic Ions and Surface Active Organic Compounds on the Adherence of Oral Streptococci. Scandinavian Journal of Dental Research, 86, 108-117. http://dx.doi.org/10.1111/j.1600-0722.1978.tb00615.x

[12] Shigemi, T., Tanaka, T., Hayashida, Y. and Maki, K. (2008) Study of Salivary Strontium and Silver Concentrations in Primary School Children Related to Dental Caries. Biological Trace Element Research, 123, 80-90. http://dx.doi.org/10.1007/s12011-007-8085-4

[13] Watanabe, K., Tanaka, T., Shigemi, T., Hayashida, Y. and Maki, K. (2009) Mn and Cu Concentrations in Mixed Saliva of Elementary School Children in Relation to Sex, Age, and Dental Caries. Journal of Trace Element in Medicine and Biology, 23, 93-99. http://dx.doi.org/10.1016/j.jtemb.2009.01.003

[14] Watanabe, K., Tanaka, T., Shigemi, T., Saeki, K., Fujita, Y., Morikawa, K., Nakashima, H., Takahashi, S., Watanabe, S. and Maki, K. (2011) Al and Fe Levels in Mixed Saliva of Children Related to Elution Behavior from Teeth and Restorations. Journal of Trace Element in Medicine and Biology, 25, 143-148. http://dx.doi.org/10.1016/j.jtemb.2011.05.003

[15] Tanaka, T., Maki, K., Hayashida, Y. and Kimura, M. (2014) Aluminum Concentrations in Human Deciduous Enamel and Dentin Related to Dental Caries. Journal of Trace Element in Medicine and Biology, 18, 149-154. http://dx.doi.org/10.1016/j.jtemb.2004.07.002

[16] British Standards Institution (1987) British Standard Specification for Safety Harnesses (Including Detachable Walking Reins) for Restraining Children When Perambulators (Baby Carriages), Push Chairs and High Chairs and When Walking. BS 6684, British Standards Institution, London.

[17] Kostyniak, P.J. (1983) Anelectrothermal Atomic Absorption Method for Aluminum Analysis in Plasma: Identification of Sources of Contamination in Blood Sampling Procedures. Journal of Analytical Toxicology, 7, 20-23. http://dx.doi.org/10.1093/jat/7.1.20

[18] Tajbakhsh, R., Joshaghani, H.R., Bayzayi, F., Haddad, M. and Qorbani, M. (2013) Association between Pruritus and Serum Concentrations of Parathormone, Calcium and Phosphorus in Hemodialysis Patients. Saudi Journal of Kidney Diseases and Transplantation, 24, 702-706. http://dx.doi.org/10.4103/1319-2442.113858

[19] Farzin, L. and Sajadi, F. (2012) Comparison of Serum Trace Element Levels in Patients with or without Pre-Eclampsia. 
Journal of Research in Medical Sciences, 17, 938-941.

[20] Kitasako, Y., Cochrane, N.J., Khairul, M., Shida, K., Adams, G.G., Burrow, M.F., Reynolds, E.C. and Tagami, J. (2010) The Clinical Application of Surface pH Measurements to Longitudinally Assess White Spot Enamel Lesions. Journal of Dentistry, 38, 584-590. http://dx.doi.org/10.1016/j.jdent.2010.04.010

[21] Enomoto, A., Tanaka, T., Kawagishi, S., Nakashima, H., Watanabe, K. and Maki, K. (2012) Amounts of Sr and Ca eluted from Deciduous Enamel to Artificial Saliva Related to Dental Caries. Biological Trace Element Research, 148, 170-177. http://dx.doi.org/10.1007/s12011-012-9368-y

[22] Putt, M.S. and Kleber, C.J. (1995) Effect of Aluminum Concentration on Dental Caries Formation in the Rat. Oral Diseases, 1, 80-85. http://dx.doi.org/10.1111/j.1601-0825.1995.tb00164.x

[23] Höök, M., Christoffersen, J., Christoffersen, M.R., Leonardsen, E.S., Rassing, M.R. and Rostrup, E. (1994) Effects of Aluminum (III) and Fluoride on the Demineralization of Bovine Enamel: A Longitudinal Microradiographic Study. Scandinavian Journal of Dental Research, 102, 198-201. http://dx.doi.org/10.1111/j.1600-0722.1994.tb01179.x

[24] Koletsi-Kounari, H., Mamai-Homata, E. and Diamanti, I. (2012) An in Vitro Study of the Effect of Aluminum and the Combined Effect of Strontium, Aluminum, and Fluoride Elements on Early Enamel Carious Lesions. Biological Trace Element Research, 147, 418-427. http://dx.doi.org/10.1007/s12011-012-9328-6

[25] Hayacibara, M.F., Ambrozano, G.M. and Cury, J.A. (2004) Simultaneous Release of Fluoride and Aluminum from Dental Materials in Various Immersion Media. Operative Dentistry, 29, 16-22.

[26] Steadman, L.T., Brudevold, F. and Smith, F.A. (1958) Distribution of Strontium in Teeth from Different Geographic Areas. The Journal of American Dental Association, 57, 340-344. http://dx.doi.org/10.14219/jada.archive.1958.0161

[27] Tepper, S.A., Zehnder, M., Pajarola, G.F. and Schmidlin, P.R. (2004) Increased Fluoride Uptake and Acid Resistance by $\mathrm{CO}_{2}$ Laser-Irradiation through Topically Applied Fluoride on Human Enamel in Vitro. Journal of Dentistry, 32, 635-641. http://dx.doi.org/10.1016/j.jdent.2004.06.010

[28] Matsunaga, T., Ishizaki, H., Tanabe, S. and Hayashi, Y. (2009) Synchrotron Radiation Microbeam X-Ray Fluorescence Analysis of Zinc Concentration in Remineralized Enamel in Situ. Archives of Oral Biology, 54, 420-423. http://dx.doi.org/10.1016/j.archoralbio.2009.01.015

[29] Watanabe, K., Nakamura, T., Ogihara, T., Ochiai, Y. and Watanabe, S. (2012) Longitudinal Evaluation of Mineral Loss at the Earliest Stage of Enamel Demineralization Using Micro-Computed Tomography. Health, 4, 334-340. http://dx.doi.org/10.4236/health.2012.46055

[30] Kleber, C.J., Putt, M.S., Smith, C.E. and Gish, C.W. (1996) Effect of Supervised Use of an Alum Mouthrinse on Dental Caries Incidence in Caries-Susceptible Children: A Pilot Study. ASDC Journal of Dentistry for Children, 63, 393402. 